\title{
SHAPE MEMORY ALLOY - MODERN SMART MATERIAL FOR VARIOUS APPLICATIONS
}

The article deals with modern materials - Shape Memory Alloys. The author presents short history of its discovery and its particular properties. One-way and two-way shape memory effects are illustrated and explained. Advantages and disadvantages of SMA are listed and possibilities of usage are discussed. There are also given some interesting applications in various fields of life illustrated by pictures and photos gathered from Internet sites.

\section{Introduction}

Shape Memory Alloys (SMA) are new very specific materials with unique properties. It has an ability to perform physical work under temperature rise or fall. This feature is due to two different internal structures that depend on the range of temperature. The goal of this paper is to characterise shape memory alloys and present some recent interesting applications.

\section{History}

In 1932 a Swedish researcher Arne Ölander observed the shape recovery abilities of a gold-cadmium alloy (Au-Cd). He gave this phenomenon the name: Shape Memory Effect (SME). Later, the same effect was observed in many other alloys like Fe-Pt, In-Tl, $\mathrm{Ni}-\mathrm{Al}, \mathrm{Cu}-\mathrm{Zn}, \mathrm{Cu}-\mathrm{Al}, \mathrm{Cu}-\mathrm{Sn}, \mathrm{Cu}-\mathrm{Zn}-\mathrm{X}$ (where $\mathrm{X}=\mathrm{Al}, \mathrm{Si}, \mathrm{Ga}$, $\mathrm{Sn}, \mathrm{Ni}$ ), $\mathrm{Cu}-\mathrm{Al}-\mathrm{X}$ (where $\mathrm{X}=\mathrm{Ni}, \mathrm{Fe}, \mathrm{Be}, \mathrm{Mn}$ ), Ni-Ti-Cu etc.

In 1950 C. Chang and T.A. Read at Columbia University in New York used X-rays to test an alloy Au-Cd and in 1958 they showed that this material can be used in mechanical systems for performing physical work.

In 1962 William J. Buehler at the U.S. Naval Ordnance Laboratory (NOL) investigated the shape memory effect in an alloy of nickel and titanium. He named this alloy briefly "NiTiNOL" (NIckel - TItanium - Naval Ordnance Laboratory) and patented its technology. This was a starting point for a great material revolution.

In 1989 Dr. Darel E. Hodgson at Shape Memory Applications, Inc., after years of experiences, began to produce high quality SMA wires that are named Flexinol.

\section{What is The Shape Memory Effect?}

The shape memory effect is caused by temperature and stress dependent shift in the material's crystalline structure changing between two different phases called martensite and austenite. Martensite, the low temperature phase, is relatively soft whereas austenite, the high temperature phase, is relatively hard. The change of state follows as a result of the heating or cooling of the alloy. During state change the phenomenon of the temperature hysteresis appears. Hysteresis width (T1 in Fig. 1) is defined as the difference between the temperatures at which the material is $50 \%$ transformed to austenite upon heating and $50 \%$ transformed to martensite upon cooling. This difference of temperatures can reach $20-30{ }^{\circ} \mathrm{C}$.

If any NiTiNOL part (Fig. 2a) is annealed at $540{ }^{\circ} \mathrm{C}$ and is allowed to cool below the phase transition temperature (Mf), the crystalline structure will change to martensite (Fig. 2b) without shape change. Now, if the part is plastically deformed (Fig. 2c), for example by bending, and then reheated above the phase transition temperature (Af), it returns to its original shape. This phenomenon is material property and is called one-way shape memory effect (Fig. 2.).

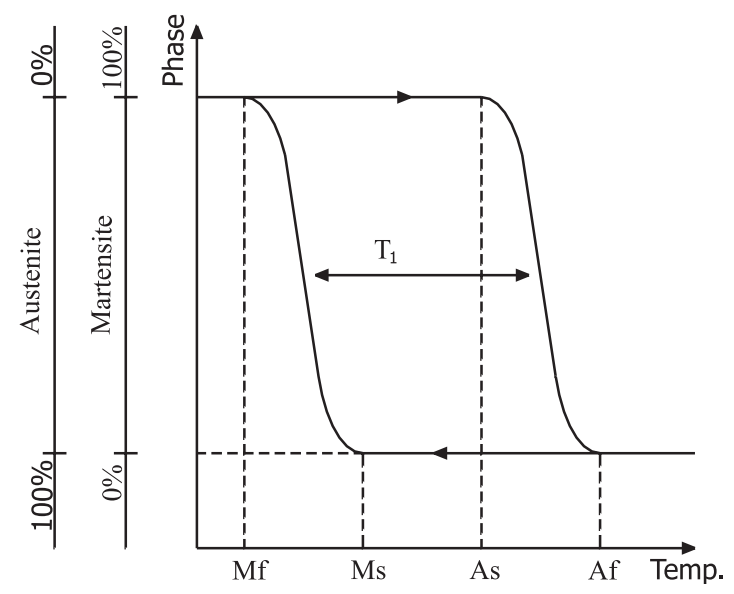

Fig. 1 Hysteresis of SME

\footnotetext{
* MSc Grzegorz Kłapyta

Silesian University of Technology, Electrical Faculty, Institute of Theoretical and Industrial Electrotechnical, Division of Mechatronics, Ul. Akademicka 10a, 44-100 Gliwice, Poland, Tel.: (+48 32) 237-28-03, Fax: (+48 32) 237-12-58, E-mail: KAPI@POLSL.GLIWICE.PL
} 
a)
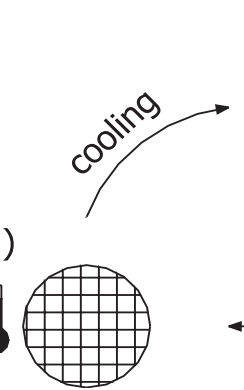
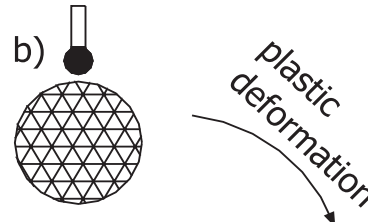

heating c)

Biomechanical and biological compatibility - unlike steel or Titan, NiTiNOL has non-linear mechanical characteristics like natural tissues: hair, bone or tendon. This causes that NiTiNOL is ideal prosthetics material. Even though it includes more Nickel (considered as toxic) than steel it is safe because in NiTi alloy intermolecular bonds are stronger and the alloy is covered with a layer of $\mathrm{TiO}_{2}$ so less Nickel is released. Experiments confirm that NiTiNOL is chemically more stable and more resistant to stain than stainless steel.

Magnetic properties - NiTiNOL is non-ferromagnetic with a lower magnetic susceptibility than stainless steel.

The following tables present basic physical and chemical parameters of NiTiNOL (Tab. 1.) and Flexinol wires (Tab. 2.)

effect (Fig 3.). Its main feature is that during a change of crystalline structure from austenite to martensite (during cooling) a sample of material also changes its shape. The material is as if it had remembered two shapes and becomes transformed between them without part of external stresses but only due to a change of temperature. However, the two way shape memory effect is no longer material property, but is acquired in technological process, which is called training. It consists of serial repetition of the following procedure:

- Max. 3\% bending in martensite;

- Heating over austenite transformation temperature (material recovers its primary shape);

- Cooling to martensite.

After many repetitions, finally we get shape memory alloy capable of recovering a pre-set shape upon heating above its transformation temperatures and returning to an alternate shape upon cooling. a)

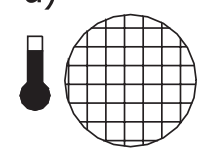

b)

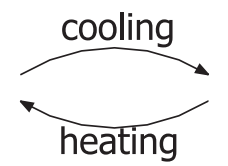

Fig. 3. Two-way shape memory effect

\section{Basic Properties}

In industrial applications only AlCuZn and NiTi alloys are being used. The latter known as NiTiNOL (or Flexinol) is used most often. Beside the above-mentioned effect it has several additional properties as e. $\mathrm{g}$.:

Superelasticity - in some temperature range (Ms $<\mathrm{T}<\mathrm{As}$ ) NiTiNOL shows its unusual elasticity and as soon as the stress is removed it returns to its original shape. The reason for this is that in this temperature range the material is over its normal martensite temperature.

Relatively constant force during decompressing in quite wide range of deformation (few \%).
Elementary properties of NiTiNOL

Tab. 1

\begin{tabular}{|l|c|}
\hline Activation start temperature & $68{ }^{\circ} \mathrm{C}$ \\
\hline Activation finish temperature & $78{ }^{\circ} \mathrm{C}$ \\
\hline Effective transition temperature & $70{ }^{\circ} \mathrm{C}$ \\
\hline Relaxation start temperature & $52{ }^{\circ} \mathrm{C}$ \\
\hline Relaxation finish temperature & $42{ }^{\circ} \mathrm{C}$ \\
\hline Annealing temperature & $540{ }^{\circ} \mathrm{C}$ \\
\hline Melting temperature & $1300{ }^{\circ} \mathrm{C}$ \\
\hline Heat capacity & $0.322 \mathrm{~J} / \mathrm{g}{ }^{\circ} \mathrm{C}$ \\
\hline Density & $6.45 \mathrm{~g} / \mathrm{cm}^{3}$ \\
\hline Energy conversion efficiency & $5 \%$ \\
\hline Max. deformation ratio & $8 \%$ \\
\hline Recommended deformation ratio & $3-5 \%$ \\
\hline Young's Modulus & $28 \mathrm{GPa}$ \\
\hline
\end{tabular}

\section{Possibility of usage}

Possible applications are based on basic properties of shape memory alloys. They are most frequently used as temperaturecontrolled actuators. Such actuator has various advantages:

- It has a very simple structure - it is small and safe,

- It offers linear movement without any transmission needed in rotary machines,

- The stroke and force can be easily modified by the selection of the SMA element,

- It works clean, silently, makes no vibrations, no dust (there is no friction), no sparks - it does not need high voltage,

- It can be safely used in very flammable environments,

- SMA element can be easily controlled in range of small movements and accelerations,

- These elements offer very high power to weight (power to volume) ratio. They can lift about thousand more than their own mass.

All this means that shape memory alloys are extremely attractive in microactuator technology. But, of course, there are some disadvantages of SMA actuators: 


\begin{tabular}{|l|c|c|c|c|c|c|}
\hline Wire diameter ((m) & 25 & 37 & 50 & 100 & 150 & 250 \\
\hline Min bend radius (mm) & 1.3 & 1.8 & 2.5 & 5.0 & 7.5 & 12.5 \\
\hline Linear resistance (Ohm/m) & 1770 & 860 & 510 & 150 & 50 & 20 \\
\hline Recommended current (mA) [1] & 20 & 30 & 50 & 180 & 400 & 1000 \\
\hline Recommended power (W/m) [1] & 0.71 & 0.77 & 1.28 & 4.86 & 8.00 & 20.0 \\
\hline Max. recovery force (N) [2] & 0.284 & 0.645 & 1.147 & 4.599 & 10.356 & 28.763 \\
\hline Rec. recovery force (N) [3] & 0.069 & 0.204 & 0.343 & 1.471 & 3.236 & 9.12 \\
\hline Rec. deformation force (N) [4] & 0.020 & 0.039 & 0.078 & 0.275 & 0.608 & 1.687 \\
\hline Min. contraction time (s) & 0.1 & 0.1 & 0.1 & 0.1 & 0.1 & 0.1 \\
\hline Relaxation time (s) & 0.1 & 0.2 & 0.3 & 0.8 & 2.0 & 5.5 \\
\hline Typical cycle rate. (cycles/min) & 55 & 52 & 46 & 33 & 20 & 9 \\
\hline
\end{tabular}

[1] In still air at $20^{\circ} \mathrm{C}$

[2] Wire stress $600 \mathrm{MPa}$

[3] Wire stress $190 \mathrm{MPa}$

[4] Wire stress $35 \mathrm{MPa}$

Low energy efficiency - the maximum theoretical efficiency of a Carnot cycle between the temperature at which a shape memory alloy finishes transforming to austenite upon heating and the temperature at which a shape memory alloy finishes transforming to martensite upon cooling is about $10 \%$. In reality, that efficiency is at least one order smaller than the theoretical Carnot value.

Limited bandwidth due to heating and cooling restrictions - shape memory actuators can be heated in different ways, radiation or conduction (thermal actuators) and by inductive or resistive heating (electrical actuators), and this is generally fast. The response speed is mainly limited by the cooling capacities.

Degradation and fatigue - the reliability of shape memory devices depends on its global lifetime performance. Parameters having strong influence on the lifetime are: time, temperature, stress value, deformation value, number of cycles, the alloy system, composition, the heat treatment, and the processing technology.

The table (Tab. 3.), presented by D. Stöckel in 1992, shows maximum values of stress and strain according to number of cycles for standard binary Ni-Ti alloys.

Maximum values of strain and stress

Tab. 3. for assumed number of cycles

\begin{tabular}{|c|c|c|}
\hline Cycles & Max. strain & Max. stress \\
\hline 1 & $8 \%$ & $500 \mathrm{MPa}_{-}$ \\
100 & $4 \%$ & $275 \mathrm{MPa}_{-}$ \\
10000 & $2 \%$ & $140 \mathrm{MPa}_{-}$ \\
$100000^{+}$ & $1 \%$ & $70 \mathrm{MPa}_{-}$ \\
\hline
\end{tabular}

Complex control - shape memory alloys show complex threedimensional thermomechanical behaviour with hysteresis. More- over, this behaviour is influenced by a large number of parameters. It follows that there are, in general, no direct and simple relations between the temperature and the position or force. Therefore, accurate position or force control by SMA actuators requires the use of powerful controllers and the experimental determination of complex data. Many mathematical models are being developed nowadays by different research groups to overcome this important limitation.

In spite of these limitations, SMA has a lot of advantages and this is why shape memory alloy actuators are widely used in many fields of life.

\section{Interesting applications}

Nowadays shape memory alloys are no longer eccentrics but they have widely entered our environment. We can meet them in everyday life and we often do not even know about their existence. The number of known applications exceeds several thousands. Shape Memory Alloys are most often used as thermostats, grippers, valves, catheters, actuators or connectors. Let's take a look at some interesting applications.

Figure 4 shows the idea of SMA usage to control position of steering flaps on aircraft's wing instead of heavy and complicated hydraulic systems. System using SMA wires is lighter and more reliable.

A submarine presented in Fig. 5 is propelled, like natural fish, by moves of its body. SMA wires and bias springs are used to contract submarine sides alternately. They are supplied with a battery and controlled by a computer stored in the nose. This kind of propulsion is very silent and such a submarine is difficult to be detected by sonar. One-meter long prototype has been already built. 


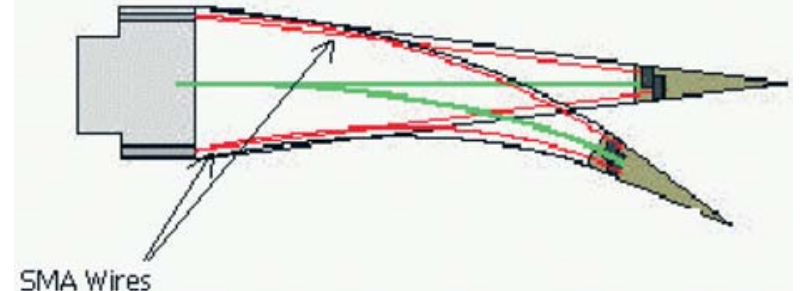

Fig. 4. SMA wires (instead of hydraulic system) manipulate a flap on the end of airplane's wing.

(http://database.cs.ualberta.ca/MEMS/sma_mems/sma.html)

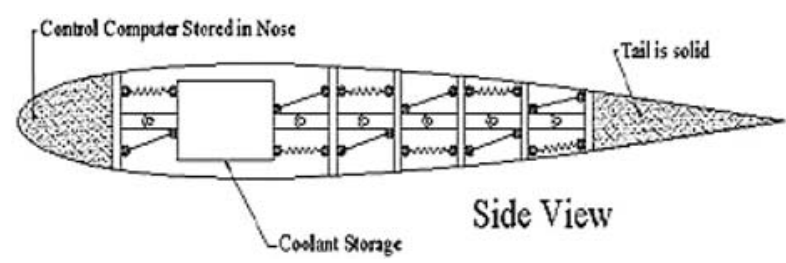

Fig. 5. Submarine propelled by SMA wires. (http://www.spacedaily.com/news)

In medicine Shape Memory Alloys are widely used for different kinds of prostheses because of their biocompatibility. But

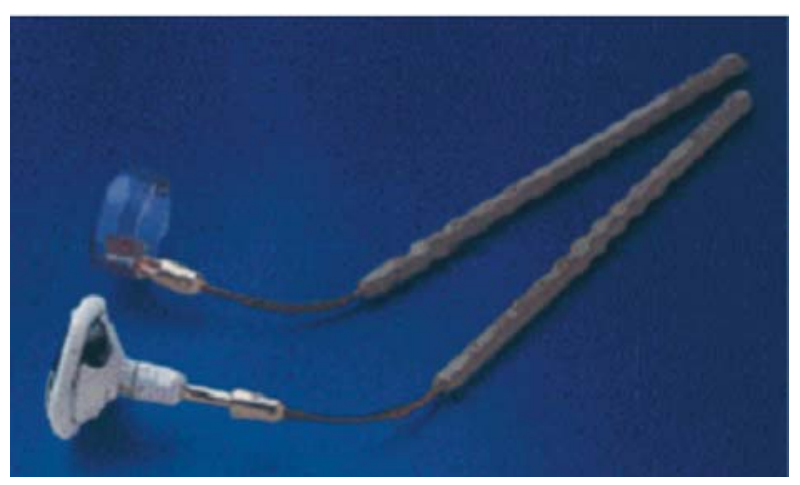

Fig. 6. Surgical tools

(http://www.sma-inc.com/StJude.html)

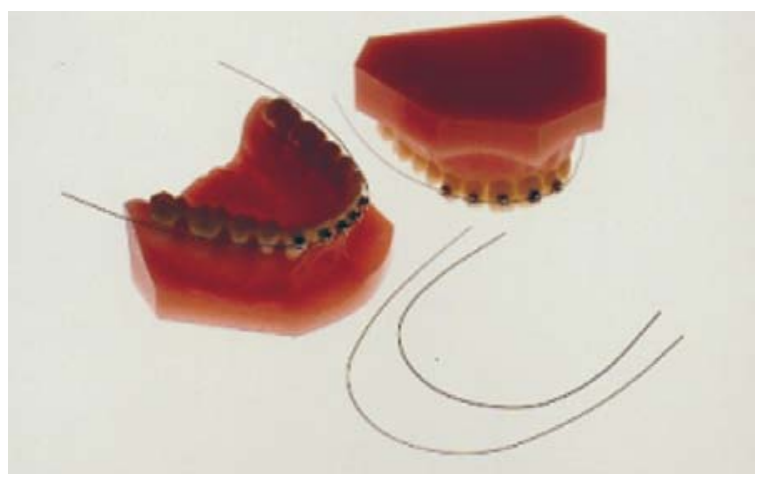

Fig. 7. Orthodontic archwires

(http://www.nitinol.com/4applications.htm) there are also other applications. Figure 6 shows surgical tools that can be easily deformed to a required shape and during sterilization process they come back to their original form. Orthodontic archwires presented in figure 7 have great advantage - they need not be regulated so often. When teeth straighten up the wires still press them in quite a wide range.

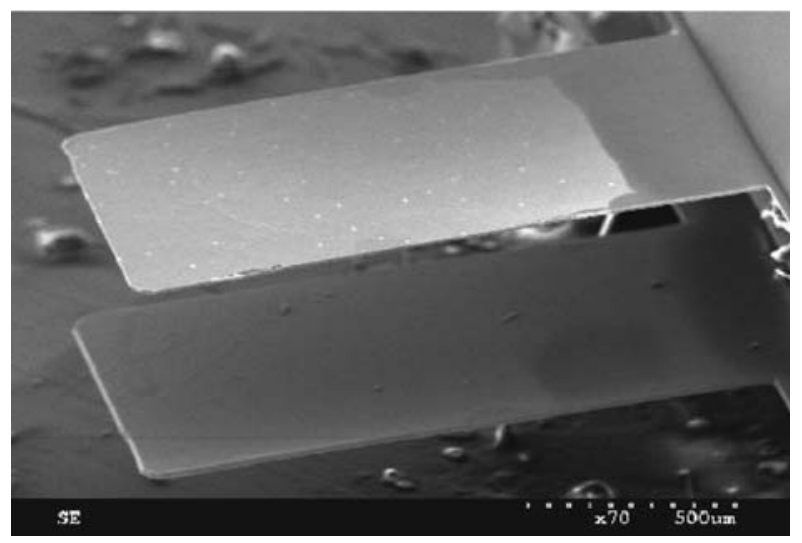

Fig. 8. Microgripper

http://www.ntu.edu.sg/mpe/Research/Programmes/MEMS/Project/ weimin 1.html\#publication

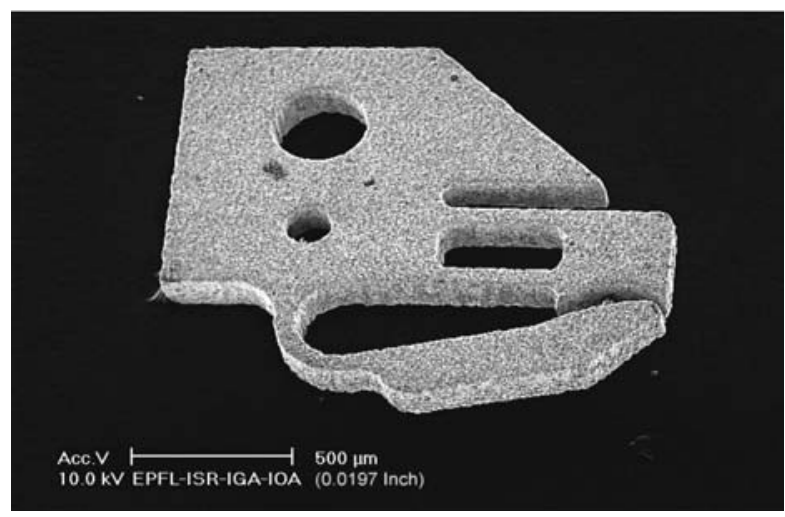

Fig. 9. Microgripper www.epfl.ch/isr/hpr

Miniature grippers can be used in medicine as well as in nanotechnology. The microgrippers presented in figures 8 and 9 are smaller than 2 millimetres.

SMA materials are very often used as thermostats in various devices - cars, coffeepots, fire systems, ventilation systems and many others. Figure 10 presents an automatic ventilation system with a thermostat using Shape Memory Alloys.

Robotics is a modern field of science and it makes use of modern technologies and materials. In robot dynamics it is very important to move quickly and precisely. It is easier to move and control a smaller mass, so SMA actuators are willingly used in robotics because of their weight to force ratio. Figures 11 and 12 present the usage of SMA wires for actuating the whole robot (Fig. 11.) or its particular parts (Fig. 12.). 


\section{kOMNlkocle}
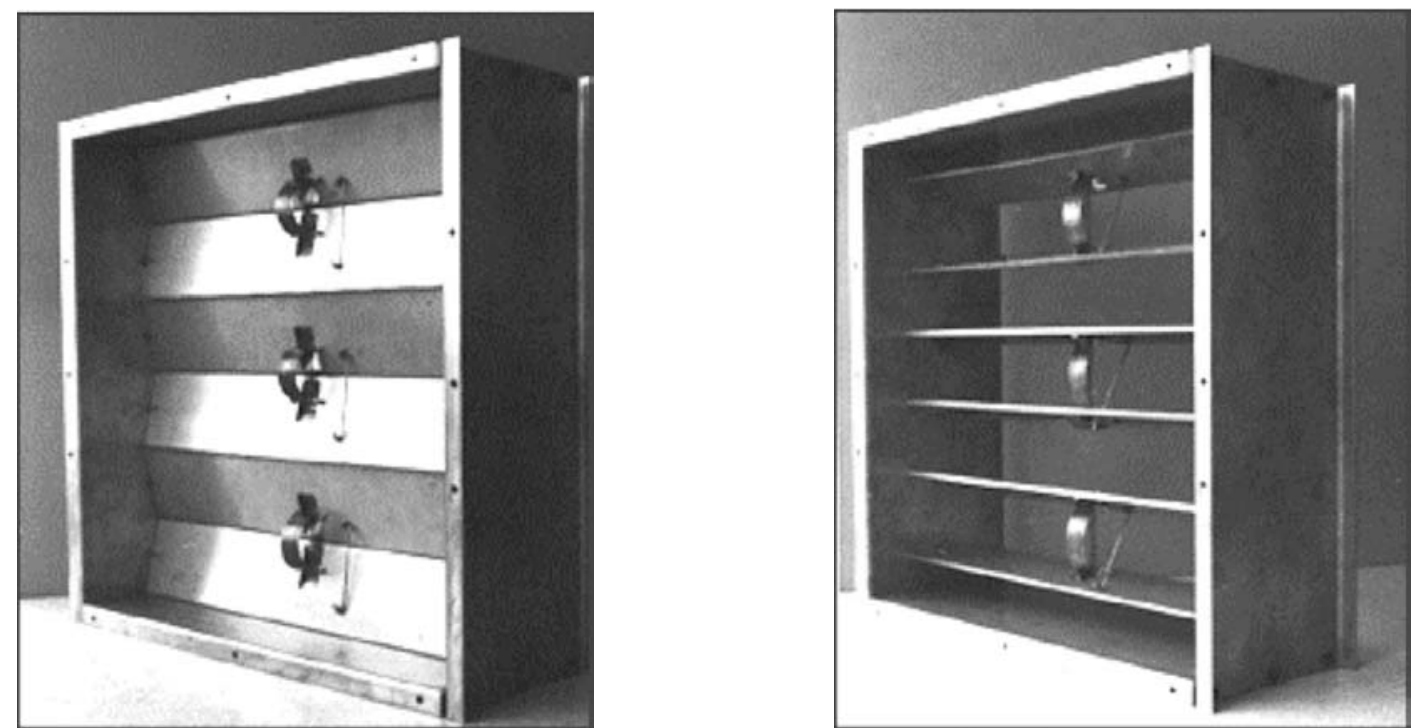

Fig.10. Self-accommodating ventilation system, closed(on the left), opened (on the right). (http://www.amtbe.com/general4.html\#app 13)

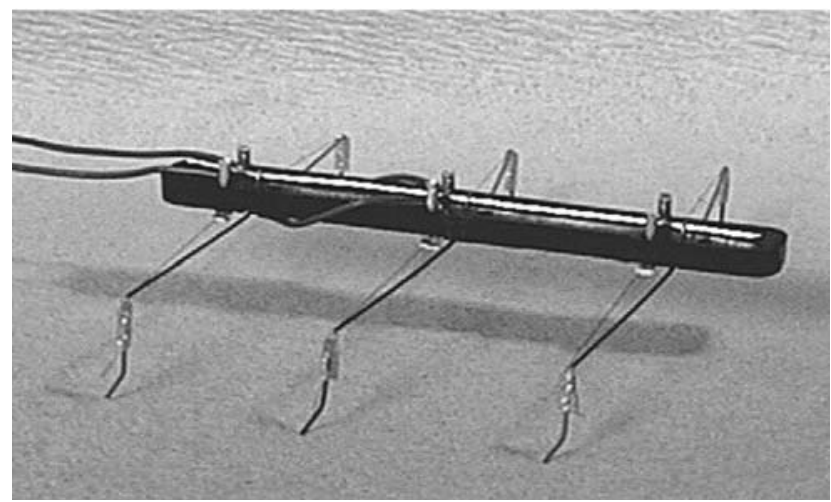

Fig. 11. Walking robot - Stiquito www.stiquito.com

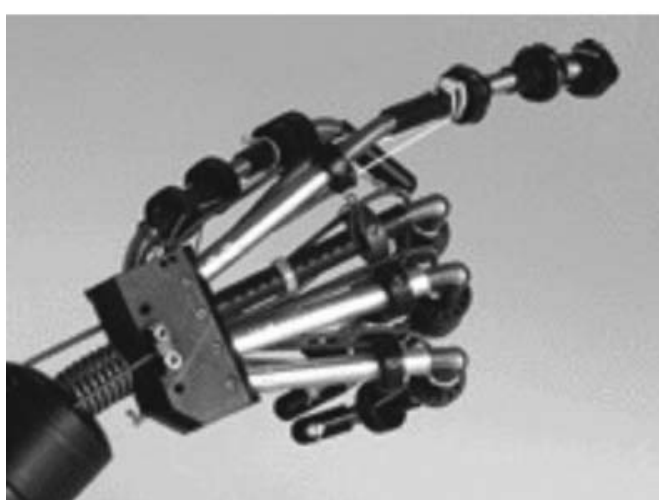

Fig. 12. Robot's hand

(http://database.cs.ualberta.ca/MEMS)

\section{References:}

[1] G. KŁAPYTA: Shape Memory Alloy Actuators In Mechatronics, Seminar on Electrical Engineering BSE '2002, 8-11 December 2002, Istebna-Zaolzie, Poland.

[2] G. KŁAPYTA: Shape Memory Alloy - Revolutionary Material For Mechatronics Applications, Transcom '2003, 23-25 June 2003, Žilina, Slovak Republic.

[3] http://www.nitinol.com/4applications.htm.

[4] http://www.totse.com/en/technology/science_technology/mslwire.html.

[5] http://www.stiquito.com.

[6] http://www.epfl.ch/isr/hpr.

[7] http://www-civ.eng.cam.ac.uk/dsl/sma/smasite.html.

[8] http://database.cs.ualberta.ca/MEMS/sma_mems/sma.html.

[9] http://www.amtbe.com.

[10] http://www.ntu.edu.sg/mpe/Research/Programmes/MEMS.

[11] http://www.sma-inc.com.

[12] http://www.dynalloy.com. 